\title{
Evaluation of techniques for delivery of steroids to lungs of neonates using a rabbit model
}

\author{
Christopher O’Callaghan, John Hardy, Julie Stammers, Terence J Stephenson, David Hull
}

\begin{abstract}
Little is known about delivery of aerosolised steroids to neonatal patients undergoing assisted positive pressure ventilation and after extubation. A rabbit model has been established to investigate factors influencing drug delivery.

Beclomethasone dipropionate, in a metered dose inhaler, was radiolabelled with technetium $99 \mathrm{~m}$. The mass median aerodynamic diameter of the aerosol was $3.3(2 \cdot 0) \mu \mathrm{m}$ and the impactor measurements confirmed that the technetium distribution corresponded with that of the drug particles. The metered dose inhaler was actuated into a collapsible spacer that was used to ventilate and deliver aerosol to anaesthetised rabbits by a tracheostomy. From each actuation of the drug 2.9 $(0.4) \%$ of the aerosol deposited in the trachea and main bronchi and $1.2(0.4) \%$ in the lung. When the drug was delivered by a spacer device, with facemask attachment, to rabbits breathing freely through a tracheostomy, aerosol deposition increased to $4 \cdot 4(2 \cdot 1) \%$ in the trachea and main bronchi and $1.9(0.9) \%$ in the lung lobes. The maximum change in systolic blood pressure after administration of aerosol by the collapsible spacer was a decrease of $13 \%$.
\end{abstract}

The methods described may prove useful for the delivery of inhaled steroids to neonatal patients likely to develop bronchopulmonary dysplasia.

Oral steroids in the form of dexamethasone have been used with some success in the treatment of bronchopulmonary dysplasia. ${ }^{12}$ However, dexamethasone given over long periods may be associated with significant side effects such as prolonged suppression of the hypothalamicpituitary-adrenal axis. ${ }^{3}$

Since their introduction, inhaled steroid aerosols have become the mainstay of treatment of asthmatic patients with moderate to severe symptoms, reducing the need for large systemic doses. The considerably smaller dose used for inhalation treatment is associated with few side effects. It is postulated that low doses of inhaled steroid started early in the management of very low birthweight infants requiring ventilation may reduce the severity of bronchopulmonary dysplasia by reducing inflammation and subsequent tissue damage.

One of the conclusions from a recent workshop on aerosol treatment in the newborn was that technical problems of delivering suspended particles by aerosol need urgent solution in view of clinical demand for topical steroid treatment by aerosol in newborns. ${ }^{4}$ The aim of this study was to use a rabbit model to assess methods of delivery of aerosolised steroids to the airways. The results of these experiments may lead to improvements in aerosol delivery to neonatal patients.

\section{Methods}

RADIOLABELLING OF BECLOMETHASONE DIPROPIONATE

Technetium $99 \mathrm{~m}$ was used to radiolabel beclomethasone dipropionate aerosol (Becotide, Allen and Hanburys). Sodium pertechnetate was extracted from saline into butanone and added to an empty beclomethasone dipropionate aerosol can. The solution was evaporated to dryness and the can cooled in liquid nitrogen. A beclomethasone dipropionate metered dose aerosol $(50 \mu \mathrm{g} /$ actuation;200 actuations/can) was also cooled in liquid nitrogen, opened, and the contents decanted into the can containing technetium $99 \mathrm{~m}$. A valve system was then crimped on to the can. At the time of dosing each can delivered approximately $1 \mathrm{MBq}$ technetium $99 \mathrm{~m} /$ actuation.

\section{PARTICLE SIZING}

A multistage liquid impinger, as described by May in $1966,{ }^{5}$ and modified by Bell et al, ${ }^{6}$ was used to measure the aerodynamic particle size distribution of the aerosol cloud. The impinger had been calibrated by sampling an aerosol of dibutyl phthalate droplets previously sized using a reference impacter (Cassella Impacter, CF, Cassella). The radiolabelled beclomethasone dipropionate preparation was fired into a Volumatic spacer device (Glaxo) with the valve closed. The spacer was plugged into the mouthpiece of the multistage liquid impinger through which air was drawn at $60 \mathrm{l} /$ minute. This was repeated 25 times. The impinger was imaged using a gamma camera and the distribution of radioactivity quantified. The study was repeated under identical conditions using non-labelled beclomethasone dipropionate metered dose inhalers. The impinger samples containing the drug were collected in methanol/water $(50 / 50)$ and assayed against a range of known concentration beclomethasone dipropionate standards using high pressure liquid chromatography.

On the basis of the data acquired for the multistage liquid impinger, together with the $50 \%$ cut off diameter for each stage of the device, a plot of aerodynamic diameter against cumulative percentage of particles below each size was 
constructed. The graph was used to calculate the mass median aerodynamic diameter (MMAD:the droplet diameter at which half the aerosol mass is contained in smaller droplets and half in larger droplets) and the geometric standard deviation (GSD:the ratio of the $84 \cdot 1 \%$ diameter to the MMAD $50 \%$ diameter). The GSD is a measure of the width of the distribution of droplet diameter.

\section{RABBIT PREPARATION}

Eight New Zealand/California rabbits were studied. A 24 gauge catheter was inserted into a marginal ear vein and anaesthesia induced with $5 \mathrm{ml} / \mathrm{kg}$ of $20 \%$ (w/v) ethyl carbamate (urethane, Sigma Chemical Co). A tracheostomy was performed and a size 3.0 endotracheal tube inserted. An 18 gauge catheter was inserted into the left carotid artery for blood pressure measurement and sampling for blood gas analysis. The catheter was kept patent by an infusion of $0.9 \%(\mathrm{w} / \mathrm{v})$ saline at $1 \mathrm{ml} /$ hour. Further doses of $20 \%(w / v)$ urethane were given as required up to a maximum dose of $8 \mathrm{ml} / \mathrm{kg}$.

\section{TIDAL VOLUME MEASUREMENT}

The tidal volume of each rabbit was measured via the tracheostomy tubes connected to a 200 litre rigid container by two tubes with internal diameters of $18 \mathrm{~mm}$ as described by Stokes $e t$ $a l .{ }^{7} \mathrm{~A}$ flow of $4 \mathrm{l} / \mathrm{minute}$ was conducted to the mask by a battery driven fan which was situated in one of the connecting tubes. This method eliminated any dead space in the system. A carbon dioxide absorber was included in the circuit. The pressure changes $\left(<1 \mathrm{~cm} \mathrm{H} \mathrm{H}_{2} \mathrm{O} / 10\right.$ $\mathrm{ml}$ ) occurring within the container as a result of the rabbit's breathing were measured by a pressure transducer (Furness Controls, FC 40) and relayed through a custom built calibration unit to a chart recorder. Calibration was carried out by injecting and withdrawing air using a 20 ml syringe.

\section{ADMINISTRATION OF RADIOLABELLED AEROSOL} TO RABBITS

\section{(a) Via collapsible spacer device}

A Laerdal resuscitation bag (Laerdal Ltd) was modified to act as a collapsible spacer. An opening was made in the base of the bag to allow access for the mouthpiece of the metered dose inhaler. The top end was fitted onto the tracheostomy tube with the rabbit lying on its back. The aerosol was then actuated into the device and immediately removed. The operators gloved hand (to protect from radioactivity on the skin) was placed over the opening at the base of the bag to act as a seal. The spacer device was then squeezed from the sides at a rate of $40 /$ minute for 30 seconds. The pressure applied was determined by observation of adequate chest wall movement. The pressure release valve of the Laerdal resuscitation bag was left in the system for safety.

Continuous blood pressure measurements were made in the four rabbits during the procedure to determine if inflation of the rabbit chest in this manor caused hypotension due to decreased venous return to the heart.

\section{(b) Via spacer device with facemask attachment} A Nebuhaler device (Astra) with facemask attachment ${ }^{8}$ was used to deliver the aerosol by a $3.0 \mathrm{~mm}$ tracheostomy tube to anaesthetised freely breathing rabbits lying on their backs. Firm card was fitted tightly around the tracheostomy tube and the mask placed onto this to create a seal to mimic placement over an infant's face. The spacer device was held in a vertical position above the tracheostomy and radiolabelled beclomethasone dipropionate actuated into the device. The rabbit was allowed to breathe through the mask for 30 seconds. This was repeated at 30 second intervals for a total of eight actuations. Tidal volume was measured before and after administration. Samples for blood gas analysis were also taken before drug delivery. This study was carried out in four rabbits.

\section{MEASUREMENT OF AEROSOL DEPOSITION}

Rabbits were killed immediately after the aerosol administration. The lungs and trachea were dissected out and separated into individual lobes and placed in a small plastic bag. The amount of radioactivity in each lobe and in the trahea and bronchi were assayed in a large volume sample counter. Individual lobes were weighed and cut into two parts, central and peripheral. These sections were reweighed and the radioactivity measured. The amount of radioactivity from a single actuation of aerosol was collected into a plastic container at the time of each experiment and used to calibrate the equipment. The counting geometry was the same during the assay of both calibration standards and the lung specimens.

Table 1 Details of rabbit weight, tidal volume, respiratory rate, and blood gases

\begin{tabular}{|c|c|c|c|c|c|c|}
\hline $\begin{array}{l}\text { Rabbit } \\
\text { No }\end{array}$ & $\begin{array}{l}\text { Weight } \\
(\text { kg) }\end{array}$ & $\begin{array}{l}\text { Tidal } \\
\text { volume (ml) }\end{array}$ & $\begin{array}{l}\text { Respiratory } \\
\text { rate/minute }\end{array}$ & $p H$ & $\begin{array}{l}\text { Arterial carbon } \\
\text { dioxide tension } \\
(\mathrm{kPa})\end{array}$ & $\begin{array}{l}\text { Arterial oxygen } \\
\text { tension } \\
(\mathrm{kPa})\end{array}$ \\
\hline $\begin{array}{l}1 \\
2 \\
3 \\
4 \\
5 \\
6 \\
7 \\
8\end{array}$ & $\begin{array}{l}3 \cdot 1 \\
3 \cdot 3 \\
3 \cdot 0 \\
2 \cdot 8 \\
2 \cdot 6 \\
2 \cdot 9 \\
3 \cdot 4 \\
3 \cdot 1\end{array}$ & $\begin{array}{c}\text { NR } \\
\text { NR } \\
\text { NR } \\
\text { NR } \\
11 \\
8 \\
7 \\
7\end{array}$ & $\begin{array}{l}(40) \\
(40) \\
(40) \\
(40) \\
78 \\
65 \\
60 \\
72\end{array}$ & $\begin{array}{l}7 \cdot 35 \\
7 \cdot 32 \\
7 \cdot 37 \\
7 \cdot 43 \\
7 \cdot 41 \\
7.4 \\
7 \cdot 46 \\
7 \cdot 48\end{array}$ & $\begin{array}{l}5 \cdot 9 \\
5 \cdot 8 \\
7 \cdot 0 \\
4 \cdot 4 \\
5 \cdot 3 \\
5 \cdot 2 \\
5 \cdot 2 \\
5 \cdot 5\end{array}$ & $\begin{array}{l}10.3 \\
10.9 \\
11.2 \\
13.0 \\
11.1 \\
10.2 \\
10.5 \\
10.6\end{array}$ \\
\hline
\end{tabular}

${ }^{*}$ Respiratory rate of rabbits $1-4$ represents rate/minute at which ventilated by collapsible spacer device. 
Results

The weight, respiratory rate, and arterial $\mathrm{pH}$ and carbon dioxide and oxygen tensions at the time of drug administration are recorded in table 1. Tidal volumes measured in the four rabbits given beclomethasone diproprionate by the spacer device with facemask attachment are also shown in table 1 .

The percentage of beclomethasone dipropionate retained in the rabbit lung and major airways when administered by the collapsible spacer and Nebuhaler device are listed in tables 2 and 3. For each dose of beclomethasone dipro-

Table 2 Proportion of beclomethasone dipropionate deposited in the rabbit lung when administered by metered dose inhaler by a collapsible spacer device

\begin{tabular}{llllll}
\hline & \multicolumn{3}{c}{$\begin{array}{l}\text { Proportion of dose }(\%) \\
\text { in rabbit No }\end{array}$} & $\begin{array}{l}\text { Mean } \\
(S D)\end{array}$ \\
\cline { 2 - 5 } & 1 & 2 & 3 & 4 & \\
\hline $\begin{array}{l}\text { Total aerosol in } \\
\text { the trachea, } \\
\text { main bronchi, } \\
\text { and lungs }\end{array}$ & 4.5 & 3.3 & 3.7 & 4.9 & $4.1(0.7)$ \\
$\begin{array}{l}\text { Aerosol deposited } \\
\text { in the trachea } \\
\text { and main bronchi }\end{array}$ & 3.0 & 2.3 & 2.8 & 3.3 & $2.9(0.4)$ \\
$\begin{array}{l}\text { Aerosol deposited } \\
\text { in lung }\end{array}$ & 1.5 & 1.0 & 0.9 & 1.6 & $1.2(0.4)$ \\
\hline
\end{tabular}

Table 3 Proportion of beclomethasone dipropionate deposited in the rabbit lung when administered by metered dose inhaler by a Nebuhaler with facemask

\begin{tabular}{llllll}
\hline & \multicolumn{3}{c}{$\begin{array}{l}\text { Proportion of dose (\%) } \\
\text { in rabbit No }\end{array}$} & $\begin{array}{l}\text { Mean } \\
(S D)\end{array}$ \\
\cline { 2 - 5 } & 1 & 2 & 3 & 4 & \\
\hline $\begin{array}{l}\text { Total in the } \\
\text { trachea, main } \\
\text { bronchi, and lungs }\end{array}$ & 5.9 & 2.9 & 8.4 & 8.0 & $8.3(2.5)$ \\
$\begin{array}{l}\text { Aerosol deposited } \\
\text { in the trachea } \\
\text { and main bronchi }\end{array}$ & 5.2 & 1.3 & 5.9 & 5.4 & $4.4(2.1)$ \\
$\begin{array}{l}\text { Aerosol deposited } \\
\text { in lungs }\end{array}$ & 0.7 & 1.6 & 2.5 & 2.6 & $1.9(0.9)$ \\
\hline
\end{tabular}

Table 4 Proportion of beclomethasone dipropionate aerosol given by collapsible spacer deposited in individual lung lobes

\begin{tabular}{|c|c|c|c|c|c|}
\hline & \multicolumn{4}{|c|}{$\begin{array}{l}\text { Proportion of lung dose in } \\
\text { each lobe }(\%) \text { in rabbit No }\end{array}$} & \multirow[t]{2}{*}{$\begin{array}{l}\text { Mean } \\
(S D)\end{array}$} \\
\hline & 1 & 2 & 3 & 4 & \\
\hline \multicolumn{6}{|l|}{ Right anterior } \\
\hline Right anterior lobe & 17 & 11 & $\begin{array}{l}33 \\
17\end{array}$ & 17 & $16(3)$ \\
\hline Right posterior lobe & 9 & 12 & 16 & 15 & $13(3)$ \\
\hline \multicolumn{6}{|l|}{ Right posterior } \\
\hline azygous lobe & 23 & 11 & 11 & 17 & $15(6)$ \\
\hline Left anterior lobe & 19 & 30 & 14 & 16 & $20(7)$ \\
\hline Left posterior lobe & 9 & 16 & 10 & 10 & $11(3)$ \\
\hline
\end{tabular}

Table 5 Proportion of beclomethasone dipropionate aerosol given by nebuhaler with facemask deposited in individual lung lobes

\begin{tabular}{lllllll}
\hline & \multicolumn{3}{l}{ Rabbit $\mathrm{No}$} & & \multirow{2}{*}{$\begin{array}{c}\text { Mean } \\
\text { (SD) }\end{array}$} \\
\cline { 2 - 5 } & 5 & 6 & 7 & 8 & \\
\hline $\begin{array}{l}\text { Right anterior } \\
\text { azygous lobe }\end{array}$ & 35 & 17 & 17 & 24 & $23(9)$ \\
$\begin{array}{l}\text { Right anterior lobe } \\
\text { Right posterior lobe }\end{array}$ & 13 & 17 & 10 & 15 & $14(3)$ \\
$\begin{array}{l}\text { Right posterior } \\
\text { azygous lobe }\end{array}$ & 14 & 15 & 20 & 13 & $14(4)$ \\
$\begin{array}{l}\text { Left anterior lobe } \\
\text { Left posterior lobe }\end{array}$ & 16 & 18 & 6 & 15 & $13(5)$ \\
\hline
\end{tabular}

pionate $2.9(0.4) \%$ of the aerosol deposited in the trachea and main bronchi and $1 \cdot 2(0 \cdot 4) \%$ in the lung when given by the collapsible spacer. For each dose of beclomethasone dipropionate $4 \cdot 4(2 \cdot 1) \%$ of the aerosol deposited in the trachea and main bronchi and $1.9(0.9) \%$ of the aerosol in the lung when given via the Nebuhaler with facemask attachment.

Deposition with in the lung lobes was calculated as the amount of aerosol per gram of tissue. Tables 4 and 5 show deposition of areosol (proportion of total lung deposition) in the individual lung lobes expressed as a percentage of total deposition in the lungs. The right lung received more aerosol $(69 \%)$ than the left lung $(31 \%)$ when administered by the collapsible spacer and when given via the Nebuhaler with facemask attachment (right $64 \%$, left $36 \%$ ). More aerosol was deposited in the upper lobes (right anterior azygous, right anterior, and left anterior, 61\%) than the lower lobes (right posterior, right posterior azygous, and left posterior lobe, $39 \%$ ) when administered by the collapsible spacer or by the Nebuhaler with facemask attachment, $58 \%$ and $42 \%$, respectively. When individual lobes were divided into peripheral and central portions 54 (3)\% of the radiolabel deposited in the lung lobes was contained in the proximal lung tissue compared with $46(3) \%$ in the peripheral tissue.

The maximum change in systolic blood pressure during and after ventilation with the collapsible spacer device was $13 \%$ and the mean (SD) systolic blood pressure 106 (12) $\mathrm{mm} \mathrm{Hg}$.

The MMAD (GSD) of the aerosol when determined from the technetium imaging data was $2 \cdot 6(2 \cdot 1) \mu \mathrm{m}$ and when determined by

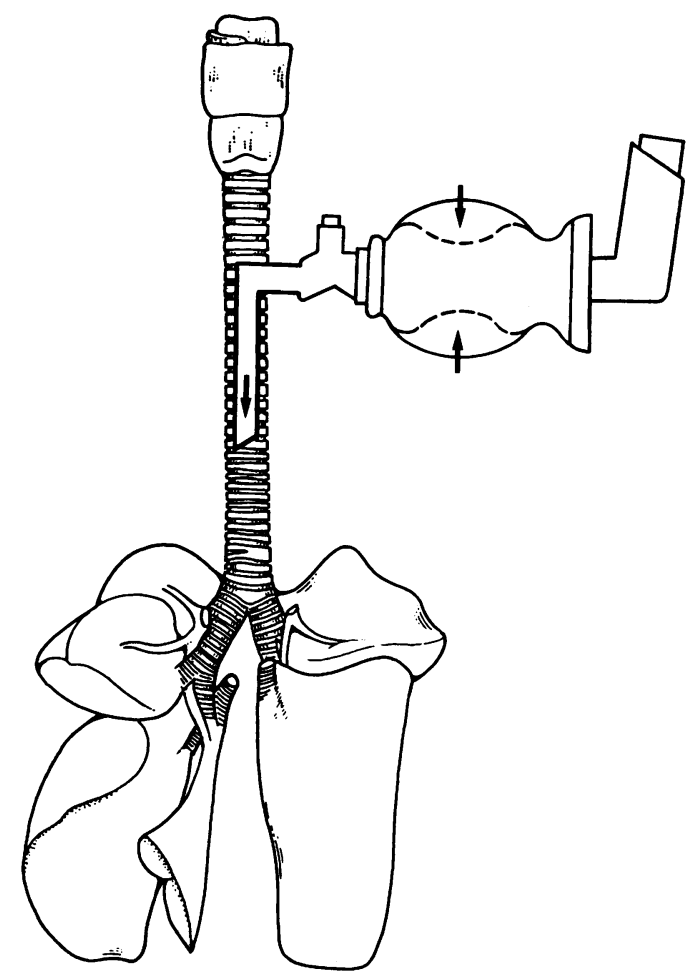

Figure 1 Administration of beclomethasone dipropionate, by a tracheostomy, to the lungs of an anaesthetised rabbit using the collapsible spacer device. 


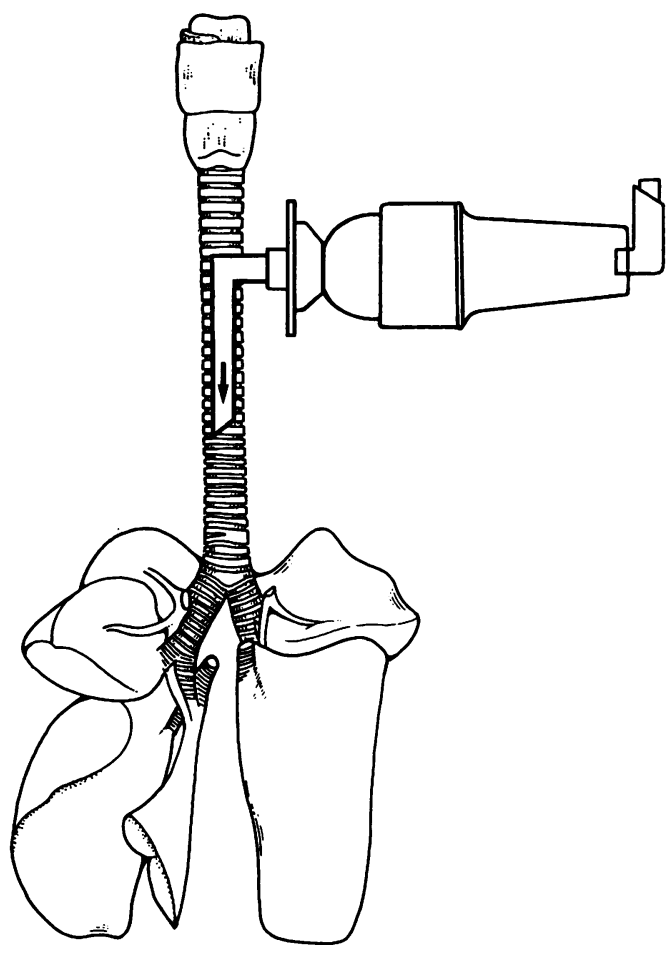

Figure 2 Administration of beclomethasone dipropionate from a spacer device with facemask attachment, by a tracheostomy, to the lungs of an anaesthetised rabbit.

assay of drug deposited with in the impinger, $3 \cdot 3(2 \cdot 0) \mu \mathrm{m}$

The method described provides satisfactory radiolabelling of beclomethasone dipropionate aerosol particles for administration from a metered dose inhaler. The particle size distribution calculated from drug assay and technetium label were similar, thus deposition of radiolabel in rabbits could be equated with drug deposition.

\section{Discussion}

The results from this pilot study are encouraging especially compared with deposition of therapeutic aerosols from metered dose inhalers in adults. Assuming a $70 \mathrm{~kg}$ adult has a good inhaler technique and achieves $10 \%$ lung deposition of actuated aerosol, the dose received from a $50 \mu \mathrm{g}$ actuation is $0.07 \mu \mathrm{g} / \mathrm{kg}$. When delivered to the rabbit by the collapsible spacer $(0.13$ $\mu \mathrm{g} / \mathrm{kg})$ or via the Nebuhaler with facemask $(0.32$ $\mu \mathrm{g} / \mathrm{kg}$ ) a considerably greater amount of beclomethasone dipropionate deposited in the rabbit lungs/ $\mathrm{kg}$ body weight. Flavin et al achieved a lung deposition of only $0 \cdot 19 \%$ in ventilated rabbits using a traditional nebuliser. ${ }^{9}$ This improved to $1.96 \%$ when the drug was delivered by a nebuliser producing submicronic particles. Using a nebulised cloud with a mass median diameter of $1.3 \mu \mathrm{m}$, Cameron et al, using standard ventilator settings, achieved lung deposition of $2 \cdot 8 \%$ of the aerosol released. ${ }^{10}$ Wattenburg et al estimated that $<1 \%$ of a nebulised test dose of sodium cromoglycate deposited in the lungs of their ventilated babies with bronchopulmonary dysplasia. ${ }^{11}$

Steroids used for nebulisation, however, are in a suspension rather than a solution and would not be released from a nebuliser generating submicronic particles. Poor clinical response seen after nebulisation of beclomethasone dipropionate suspension in asthmatic children may be explained by the low amount of steroid that is contained in particles likely to reach the airways. ${ }^{12}$ A suspension of budesonide, suitable for nebulisation, has recently become available at a concentration 10 times that of the beclomethasone dipropionate suspension. In a ventilated lung model deposition of drug ranged from $0.06 \%$ to $2 \cdot 7 \%$ depending on the nebuliser used. ${ }^{13}$

Greater deposition was seen in the upper lobes of the rabbits, which is similar to findings in other animal studies. This preferential deposition has been shown to be independent of body position. ${ }^{14}$ Compared with instillation of drug into the lungs, however, delivery by aerosol results in a much more homogeneous deposition. ${ }^{15}$ It was encouraging that over $40 \%$ of the drug depositing in a lung lobe reaches the outer half. A recent study of ventilated adult patients showed poor lung delivery after nebulisation $(1 \cdot 2 \%$ of the initial dose), but much better delivery $(5 \cdot 6 \%$ of initial dose) when the drug was given from a metered dose inhaler via a spacer chamber contained within the ventilator circuit. ${ }^{16}$ Because neonates have much smaller endotracheal tubes the percentage of the initial total dose entering the lungs may be considerably less. The patient does not have to be disconnected from the ventilator circuit, however, which may be advantageous. In practice a neonatal patient receiving steroid aerosol by the collapsible spacer would have to be disconnected only twice a day. This should prove acceptable as ventilated babies are hand ventilated during suction of the endotracheal tube without apparent deleterious effect.

Once the neonatal patient is extubated, inhaled steroids may be continued using a spacer device with facemask attachment. Studies are required to determine the upper airway deposition of steroid in neonatal patients. The dose of steroid reaching the airways of neonatal patients may be considerably lower than seen in the present study if there is enhanced upper airway deposition. A pilot study involving the treatment of chronically wheezing infants with a steroid aerosol given by a spacer device with facemask attachment showed a very encouraging improvement in symptoms. ${ }^{17}$ Asthmatic children aged 1-3 years have also shown improvement in symptoms in response to steroids delivered in this way. ${ }^{18}$

The adult rabbit as a model has limitations, as the lungs are usually normal and the pattern of airway branching differs from that of human airways. The model, however, provides a simple in vivo method of comparing aerosol deposition of various aerosols from different devices. This is preferable to studying radiolabelled aerosol deposition in large numbers of neonatal patients.

1 Cummings JJ, D'Eugenio DB, Gross SJ. A controlled trial of dexamethasone in preterm infants at high risk for bronchodexamethasone in preterm infants at high risk for bronc
pulmonary dysplasia. $N$ Engl $\mathcal{F}$ Med 1989;320:1505-10.

2 Katz R, McWilliams B. Bronchopulmonary dysplasia in the pediatric intensive care unit. Crit Care Clin 1988;4:755-87. 
3 Alkalay AL, Puri AR, Lin BJC, Vinstein AL, Neufeld ND, Klein AH. Hypothalamic pituitary-adrenal axis function in very low birth weight infants treated with dexamethasone. Pediatrics 1990;86:204-10.

4 Silverman M. Aerosol therapy in the newborn. Report of a workshop. Arch Dis Child 1990;65:906-8.

5 May KC. Multistage liquid impinger. Bacteriology Reviews 1966;30:559-70.

6 Bell JH, Brown K, Glasby J. Variation in delivery of isoprenaline from various pressurised inhalers. $\mathcal{F}$ Pharm isoprenaline from various press
Pharmacol $1973 ; 25$ (suppl):32P-6.

7 Stokes GM, Milner AD, Wilson AJ, Morgan DB, Carman PGT, Oliver MR. Ventilatory response to increased dead PGT, Oliver MR. Ventilatory response to increased dead space

8 O'Callaghan C, Milner AD, Swarbrick A. Spacer device with face mask attachment as a drug delivery system for young asthmatics. BMF 1989;298:160-1.

9 Flavin M, MacDonald M, Dolovich M, Caotes G, O'Brodovich $\mathrm{H}$. Aerosol delivery to the rabbit lung with an infant ventilator. Pediatr Pulmonol 1986;ii:35-9.

10 Cameron D, Arnot R, Clay M, Silverman M. Aerosol delivery in neonatal ventilator circuits. A rabbit model. Pediatr Pulmonol 1991;10:208-13.
11 Wattenburg KL, Clark AR, Kelly HW, Murphy S. Delivery of aerosolised medication to intubated babies. Pediatr Pulmonol 1991;10:136-41.

12 O'Callaghan C. Particle size of beclomethasone dipropionate produced by two nebulisers and two spacing devices. Thorax 1990;45:109-11.

13 Cameron D, Clay M, Silverman M. Evaluation of nebulisers for use in neonatal ventilator circuits. Crit Care Med 1990; 18:866.

14 Sneddon SL, Brain JD, LeMott SR, Valberg PA. Factors influencing aerosol deposition in small animals. Federation influencing aerosol deposition in small animals. Federation

15 Brian JD, Knudson DE, Sorokin SP, Davis MA. Pulmonary distribution of particles given by intratracheal instillation or by aerosol inhalation. Environ Res 1976;11:13-33.

16 Fuller HD Dolovich MB, Posmituck G, Wong Pack W, Newhouse MT. Pressurised aerosol versus jet aerosol delivery to mechanically ventilated patients. Am Rev Respir Dis 1990;141:440-4.

17 O'Callaghan C, Milner AD. Inhaled steroids from a face mask and spacer device in infancy. Lancet 1989;i:1458.

18 Bisgaard H, Munck SL, Nielsen JP, Peterson W, Ohlsson SV. Inhaled budesonide for treatment of recurrent wheezing in early childhood. Lancet 1990;336:649-51. 